RESEARCH ARTICLE

\title{
The effect of potato variety mixtures on epidemics of late blight in relation to plot size and level of resistance
}

\author{
S.L. Phillips ${ }^{1}$, M.W. Shaw ${ }^{2} \&$ M.S. Wolfe ${ }^{1}$ \\ 1 Elm Farm Research Centre, Hamstead Marshall, Near Newbury, Berkshire, UK \\ 2 School of Plant Sciences, The University of Reading, Whiteknights, Reading, Berkshire, UK
}

\author{
Keywords \\ Disease management; diversification; \\ genotype unit area; monoculture; \\ Phytophthora infestans; \\ Solanum tuberosum.

\section{Correspondence} \\ M.W. Shaw, School of Plant Sciences, \\ The University of Reading, Whiteknights, \\ Reading, Berks RG6 6AU, UK. \\ Email: m.w.shaw@reading.ac.uk
}

Received: 7 June 2005; revised version accepted: 14 September 2005.

doi:10.1111/j.1744-7348.2005.00027.x

\begin{abstract}
Potatoes of a number of varieties of contrasting levels of resistance were planted in pure or mixed stands in four experiments over 3 years. Three experiments compared the late blight severity and progress in mixtures with that in pure stands. Disease on susceptible or moderately resistant varieties typical of those in commercial use was similar in mixtures and pure stands. In 2 of 3 years, there were slight reductions on $\mathrm{cv}$. Sante, which is moderately susceptible, in mixture with cv. Cara, which is moderately resistant. Cara was unaffected by this mixture. Mixtures of an immune or near-immune partner with Cara or Sante substantially reduced disease on the latter. The effect of the size of plots of individual varieties or mixtures on blight severity was compared in two experiments. Larger plots had a greater area under the disease progress curve, but the average rate of disease progress was greater in smaller plots; this may be because most disease progress took place later, under more favourable conditions, in the smaller plots. In one experiment, two planting densities were used. Density had no effect on disease and did not interact with mixture effects. The overall conclusion is that, while mixtures of potato varieties may be desirable for other reasons, they do not offer any improvement on the average of the disease resistance of the components.
\end{abstract}

\section{Introduction}

Large plantings of single genotypes dominate modern cropping systems. Such production systems are convenient, but can favour plant disease epiphytotics. The vulnerability of single genotypes is well illustrated by the late blight epidemics that devastated Irish potato production in the 1840s (Bourke, 1964). These epidemics resulted from the introduction of Phytophthora infestans into crops of a susceptible variety (cv. Lumper) grown across large areas. Such uniformity contrasts with natural ecosystems in which host genotypes are usually both locally diverse and distributed in small patches (Jarosz \& Burdon, 1991); this means that natural ecosystems are usually less prone to rapid and severe epidemics.

The intimate mixing of varieties is a proven method in certain cropping systems of introducing diversity to reduce plant disease (Wolfe, 1985; Akem et al., 2000; Zhu et al., 2000). Variety mixtures may reduce disease in three basic ways (see Finckh \& Wolfe, 1998; Mundt, 2002): (a) resistance induction, by avirulent spores preventing or delaying infection by adjacent virulent spores; (b) barrier effects, with resistant plants acting as barriers to pathogen spread and (c) dilution of susceptibles, where there is an increased distance between plants of the most susceptible component for any particular pathogen genotype. Garrett \& Mundt (1999) suggest five key characteristics of host-pathogen systems that predict host-diversity effects leading to reduced disease: (a) a small genotype unit area (GUA), by which is meant the area of a patch in the crop in which plant tissue has identical genetic composition; (b) a shallow dispersal gradient of pathogen spores; (c) small lesion size; (d) short pathogen generation time and (e) strong host specialisation. Hence, there are inherent characteristics of both the host and pathogen that optimise mixture responses. These characteristics are common in small-grained cereals affected by rusts and mildews (Wolfe, 1985). However, potatoes are large, broad-leaved 
plants, $P$. infestans causes large spreading lesions and most functional potato resistance to $P$. infestans is considered race nonspecific. (R-genes are commonly present, but virulence against all known R-genes is common, so they do not determine the observed resistance level of a cultivar.) These are all factors that should limit the usefulness of induced resistance, barrier effects and the dilution of susceptibles in variety mixtures.

Nonetheless, there has been some recent interest in the use of potato variety diversification to reduce late blight. Andrivon et al. (2003) found that late blight severity on a susceptible cultivar was significantly lower when the cultivar was grown in rows alternating with partially resistant cultivars than when it was grown alone. They showed that this was the result of cumulative effects over the course of the epidemic. In the USA, Garrett $\delta$ Mundt (2000) found that disease severity on the susceptibles was reduced by around $37 \%$ in intimately mixed plots of 10 susceptible and 26 resistant potato plants. However, in Ecuador, Garrett et al. (2001) reported less convincing evidence of the effects of mixing potato varieties against late blight, with a large host-diversity effect for reduced disease only at the site most distant from commercial potato production.

Mundt (2002) points out the importance of spatial scale, in terms of plot size, in determining how mixtures affect disease. He explains that mixture efficacy is greater in production-scale situations than in small-scale experimental plots. One reason for this is that interplot interference is particularly important in variety mixture trials as the effect of reducing the pathogen's infection efficiency through dilution of inoculum can be negated by large amounts of external inoculum. Another reason is that focus expansion is faster in a pure stand than in a mixture, but this only causes a difference if it takes a focus a substantial time to cover a field.

The autoinfection/alloinfection ratio is central to mixture performance, as mixtures are unlikely to have significant effects on disease unless there is substantial exchange of inoculum among different host genotypes in the population (Mundt, 2002). Autoinfections are those in which the donor is the same as the recipient and alloinfections are those in which the donor is different from the recipient. The GUA affects this ratio, as alloinfection increases with decreasing GUA so that mixture effects are favoured by smaller GUA (Mundt \& Leonard, 1985). This can be further explored by examining the effects of planting density. Host diversity effects would be expected to be greater at higher planting densities because single genotypes, make up smaller areas as density increases and autoinfection should be reduced (Garrett $\&$ Mundt, 1999).

Therefore, study of potato variety mixture performance should address aspects of spatial scale and the effects of different autoinfection : alloinfection ratios at different planting densities, in different variety combinations. An improved understanding of the effect of potato variety mixtures on late blight is important because such mixtures may have a role to play in a durable 'systems approach' to disease management in low input agricultural systems (Mundt et al., 2002). Variety diversification may also help to reduce pesticide input in conventional systems (Andrivon et al., 2003).

\section{Materials and methods}

The site used for the trials is a certified (UK5) organic farm (Grid Ref: TM280790). The soil has a medium texture, with approximately $20 \%$ clay and a typical pH of 7.5 . Composted horse manure at $25 \mathrm{t} \mathrm{ha}^{-1}$ was incorporated around 2 weeks before planting, $35 \mathrm{~kg} \mathrm{ha}^{-1}$ of potassium sulphate was incorporated prior to trials in 2002 and all trials followed the leguminous phase of a rotation. The trials were not irrigated, and both pre- and postemergence weeding was achieved with inter-row cultivation and reridging. Unless otherwise stated, the planting depth was around $10 \mathrm{~cm}$, with a $35 \mathrm{~cm}$ plant spacing within rows and $75 \mathrm{~cm}$ between rows, similar to common grower practice. Several varieties were used (Table 1), chosen to provide diverse foliage late blight resistance; as the work developed, different subsets of varieties were used in successive years. In particular, the most resistant varieties were not initially available. Most of the varieties are known to possess some R-genes, although in all varieties except Appell and Tominia these are routinely overcome by UK populations of Phytophthora infestans. Resistance in Appell sometimes resembles the hypersensitive response associated with major gene resistance, so it may contain an R-gene that is functional in some seasons in the UK. Tominia demonstrates characteristics of both race-specific and race nonspecific resistance responses (D. Shaw, personal communication).

Late blight severity was assessed visually using the key of W.E. Fry (http://ppathw3.cals.cornell.edu/Fry/ protocols.htm, based on James, 1971). Disease severity was summarised as area under the disease progress curve (AUDPC; Campbell \& Madden, 1990) and rate of disease progress, calculated as the slope coefficient of a regression of logit transformed of disease severity against time.

\section{Effect of plot size on disease in variety mixtures}

A trial was planted during the last week of April 2001 to fulfil various purposes. That relevant here was to examine the effect of plot size on potato late blight epidemics in varietally pure or mixed crops of potato; other data from the same field are reported in Phillips (2004). The trial 
Table 1 The characteristics of varieties used

\begin{tabular}{llll}
\hline & & Foliage Late & Tuber Characteristics \\
Variety & Growth Habit & Blight Resistance & White with pink spots \\
Verity & Very erect & High & White, kidney shaped \\
Nicola & Semierect & Low & Red, round \\
Robinta & Semierect & Medium & White with pink spots \\
Cara & Very erect & High & White, round 2001 \\
Sante & Spreading to semierect & Low to medium & White, round 2002, 2002, 2003 \\
Appell & Spreading to semierect & High & White, round \\
Milva & Spreading to semierect & Low to medium & Purple, oval 2002, 2003 \\
Tomina & Very erect & Very high & 2003 \\
\hline
\end{tabular}

was a split-plot design. Main plots had large $(9 \times 7.5 \mathrm{~m})$ or small $(4.5 \times 4.5 \mathrm{~m})$ subplots. Each subplot contained either a pure variety or an equiproportionate mixture of two to five varieties; a complete set of variety treatments were randomised within each main plot. For logistical reasons, only two replicates were possible. Details of the variety mixtures and agronomy used are given in Phillips (2004). Varieties were compatible agronomically and had a range of foliage resistance to late blight. Late blight arrived as a natural infection around 9 August 2001. Severity was assessed visually on 9, 15, 20, 24, 28 August and 1 September.

In 2002, four varieties of potato with diverse foliage resistance levels against late blight (Table 1) were planted in plots of three sizes. Large plots were $5.25 \times 11.5 \mathrm{~m}$, medium plots were $11.5 \times 3 \mathrm{~m}$ and small plots were $5.75 \times 1.5 \mathrm{~m}$. The total area of each variety in each replication in small plots (28 plots replicate ${ }^{-1}$ ), medium plots ( 8 plots replicate ${ }^{-1}$ ) and large plots (4 plots replicate $^{-1}$ ) was approximately $60 \mathrm{~m}^{2}$. The plots were arranged within and between blocks so that, as far as possible, no variety appeared next to itself. There were three replicates. It was planted on 29 April 2002. Late blight arrived as a natural infection around 17 July 2002. Late blight was scored on 17, 23 and 31 July, and 6 and 13 August 2002. The data were analysed using analysis of variance (ANOVA) in Genstat, one variety at a time.

\section{Effect of planting density on disease in variety mixtures}

This split-plot trial was designed to examine the effects on potato late blight of two-way variety mixtures at three planting densities. Planting began on 29 April 2002. Main plots were $10 \mathrm{~m}$ long $\times 7.5 \mathrm{~m}$ wide, with at least $1 \mathrm{~m}$ gaps, (occupied by oats) between plots. The trial contained six replications; willow trees separated replications across the trial. The main plot factor was planting density, with three levels, achieved by planting at 25, 35 and $45 \mathrm{~cm}$ spacings within rows. The split-plot treatment factor had three levels: pure stands and a two-way ran- dom mixture of the varieties Cara and Sante. Late blight arrived as a natural infection around 13 July 2002. Late blight was scored on the 13, 17, 23, 30 July and 5 August 2002. AUDPC and rate were analysed in each variety separately using a split-plot ANOVA procedure in Genstat.

\section{The effects of two-way variety mixtures}

This trial examined the performance of four maincrop varieties (Cara, Appell, Sante and Tominia) in pure stands and in all two-way mixture permutations (Table 1). Additional treatments were provided by mixing Cara and Sante with Tominia in the ratio $1: 3$. The trial had five blocks with 18.5-m-long and 7.5-m-wide plots, with a $1.5-\mathrm{m}$ gap between plots. The varieties were chosen based on results from previous trials to diversify for late blight resistance, to diversify for growth characteristics and to provide distinct tubers for separation at harvest (Table 4). Late blight arrived as a natural infection and was first scored on 1 August 2003. Plots were scored on 8, 12, 18, 28 August and 3 September 2003.

\section{Results}

\section{Effect of plot size on disease in variety mixtures}

Preliminary results from the 2001 experiment were summarised in Phillips (2002). There was no significant interaction in AUDPC between plot size and mixture composition. In cv. Verity, the most resistant, the AUDPC increased with the number of components in the mixture $(P<0.01)$, but in other varieties, any trend was not significant. Larger plots had about $100 \%$-days more AUDPC on all varieties, regardless of their resistance level, in all mixtures (Table 2). This is not formally significant, but the power of the test is very low because of the shortage of degrees of freedom for error at the main plot level. There were no significant differences in rates of disease progress related either to plot size or to composition.

Fig. 1 shows that in 2002, the GUA again influenced the severity of late blight. In cvs. Milva, Robinta and 
Table 2 Averages of area under disease progress curves (\%-day) of late blight on each variety growing in pure stands and two-component mixtures in plots of two different sizes in 2001

\begin{tabular}{|c|c|c|c|c|c|}
\hline \multirow[b]{2}{*}{ Variety } & \multicolumn{3}{|c|}{ Plot Type } & \multicolumn{2}{|c|}{ Plot Size $^{a}$} \\
\hline & Pure $^{b}$ & Mix & Partners in Mixture Plots & $68 \mathrm{~m}^{2 \mathrm{c}}$ & $20 \mathrm{~m}^{2}$ \\
\hline Cara & 659 & 648 & All & 707 & 594 \\
\hline Sante & 869 & 878 & Not Robinta & 892 & 860 \\
\hline Verity & 767 & 693 & All & 785 & 650 \\
\hline Robinta & 1300 & 1172 & Cara, Verity & 1233 & 1176 \\
\hline Nicola & 450 & 480 & Not Robinta & 501 & 446 \\
\hline
\end{tabular}

${ }^{a}$ Main effects of mixture and size only are shown; interactions were not significant.

${ }^{b}$ For comparisons between pure varieties or mixtures, SED 65, 64 d.f.

${ }^{\mathrm{c}}$ For comparisons between plot sizes, SED 99, 10 d.f.

Sante, late blight was least severe in the small plots and most severe in the large plots. In all varieties, there were significant differences $(P<0.01)$ in AUDPC between plot sizes (Table 3). In Milva, Robinta and Sante, small plots reached a diseased leaf area of $30 \%$ more than 6 days later than large plots. The more resistant variety, Appell, had little late blight; small plots had nonsignificantly more disease than medium and large plots. The rate of disease progress in Robinta and Sante differed significantly different between plot sizes, with disease progress faster in smaller plots (Table 4). Averaged over varieties, the rate of disease progress was greater in the small plots than in the large plots.

\section{Effect of planting density on disease in variety mixtures}

There were no interactions between the effects of mixing and planting density on either rate or AUDPC in either variety. Planting density did not affect disease in either variety (Fig. 2). AUDPC in Cara was similar in pure stands and mixtures, but in Sante, there was significantly less disease in mixtures (Fig. 2B).
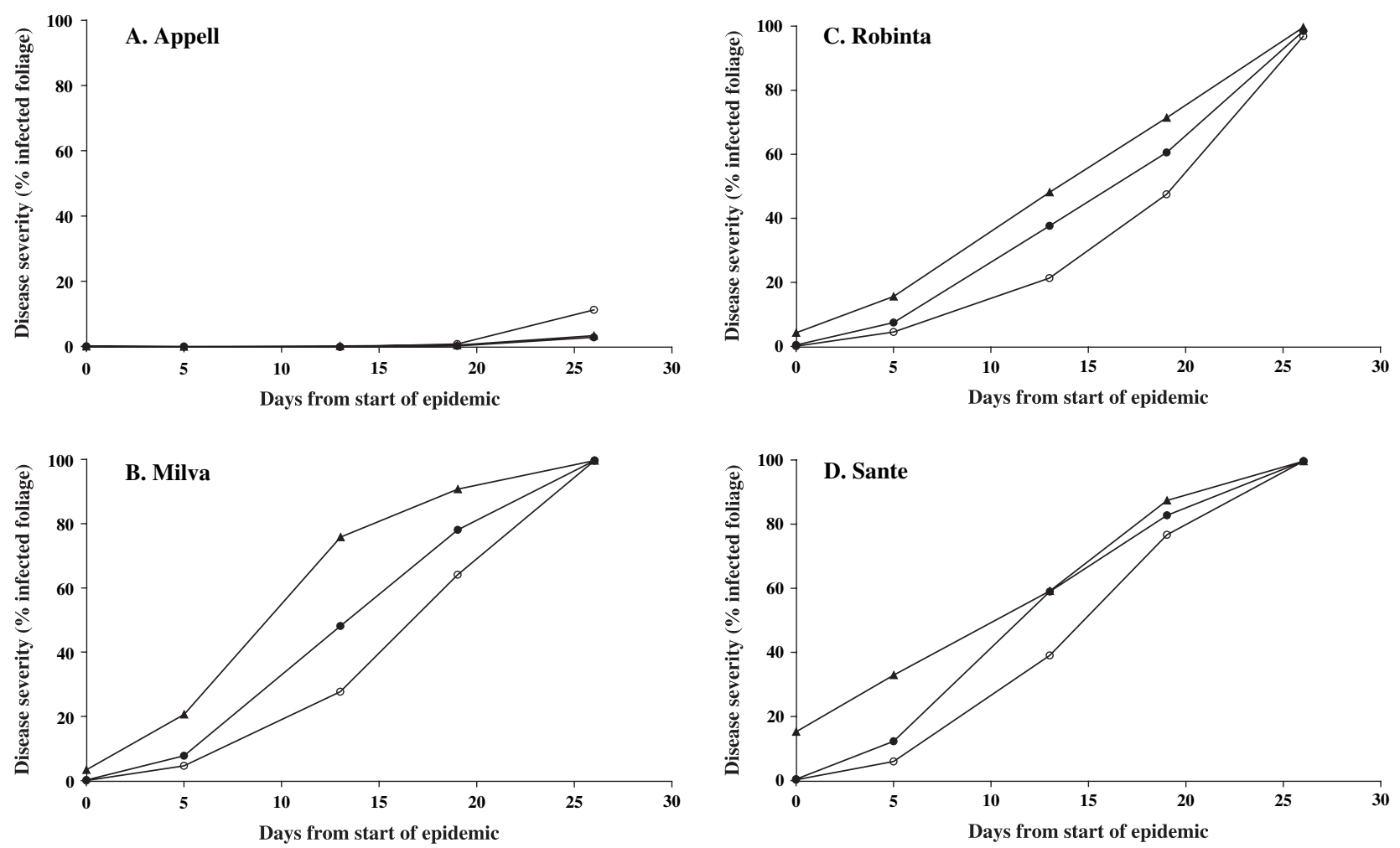

Figure 1 Disease epidemic curves for potato late blight on cvs. Robinta, Sante, Milva and Appell grown in single-variety plots of varying size in 2002. o, 9-m² plots; $\bullet, 34-\mathrm{m}^{2}$ plots; $\boldsymbol{\Delta}$, 63- $\mathrm{m}^{2}$ plots. 
Table 3 Area under disease progress curves (\%-day) of late blight on four varieties growing in pure stands of three different plot sizes in 2002

\begin{tabular}{lcccl}
\hline Variety & $63-\mathrm{m}^{2}$ Plots & $34-\mathrm{m}^{2}$ Plots & $9-\mathrm{m}^{2}$ Plots & SED $^{\mathrm{a}}$ \\
\hline Robinta & 1448 & 1109 & 868 & $112, P<0.001$ \\
Sante & 1753 & 1462 & 1226 & $168, P<0.01$ \\
Milva & 1712 & 1316 & 1042 & $121, P<0.001$ \\
Appell & 20 & 14 & 48 & $15, P<0.01$ \\
Mean & 869 & 841 & 713 & \\
\hline
\end{tabular}

${ }^{a}$ All single-variety SED have 25 d.f.

\section{The effects of two-way variety mixtures}

In 2001, the AUDPC in pure stands was essentially the same as in two-way mixtures, for all varieties (Table 2 ). In 2002, Sante had less disease in mixtures than in pure stands (Fig. 2), but for Cara, there was no difference in disease severity between pure stands and mixtures.

In 2003, there was negligible disease on Appell and Tominia, but late blight reached $100 \%$ in some plots containing Sante and $30 \%$ in some plots containing Cara. There were significant differences in disease severity on both Cara and Sante according to whether or not they were grown in pure stands, in mixtures with Appell, in mixtures with Tominia or in 1:3 mixtures with Tominia (Table 5). Both Cara and Sante plants had more disease in pure stands than in mixtures with the resistant varieties Appell and Tominia. Compared to pure stands, Sante had $49 \%$ higher disease severity when mixed with Cara and 53\% lower disease severity when mixed with Appell. The best performing Cara mixture was with Appell; this mixture provided an $82 \%$ reduction in disease severity on Cara.

\section{Discussion}

In the present study, in both 2001 and 2002, the severity of late blight on potatoes was less in small plots than in larger plots. In modelling the effects of plot size on the apparent infection rate of late blight, Paysour \& Fry (1983) found

Table 4 Analysis of the logistic disease progress rates for potato late blight on four varieties at three different plot sizes in 2002. There were significant differences between plot sizes for Robinta and Sante and for the mean of all the varieties

\begin{tabular}{lllll}
\hline Variety & $\begin{array}{l}63-\mathrm{m}^{2} \\
\text { Plots }\end{array}$ & $\begin{array}{l}34-\mathrm{m}^{2} \\
\text { Plots }\end{array}$ & $\begin{array}{l}9-\mathrm{m}^{2} \\
\text { Plots }\end{array}$ & SED $^{\mathrm{a}}$ \\
\hline Robinta & 0.24 & 0.36 & 0.43 & $0.039, P<0.01$ \\
Sante & 0.28 & 0.38 & 0.39 & $0.034, P<0.05$ \\
Milva & 0.43 & 0.47 & 0.50 & N.S. \\
Appell & 0.28 & 0.54 & 0.56 & N.S. \\
Mean & 0.31 & 0.44 & 0.47 & $0.044, P<0.01$ \\
& & & & $(115$ d.f. $)$ \\
\hline
\end{tabular}

${ }^{\mathrm{a}}$ SED for single varieties have 25 d.f., for the mean 115 d.f.
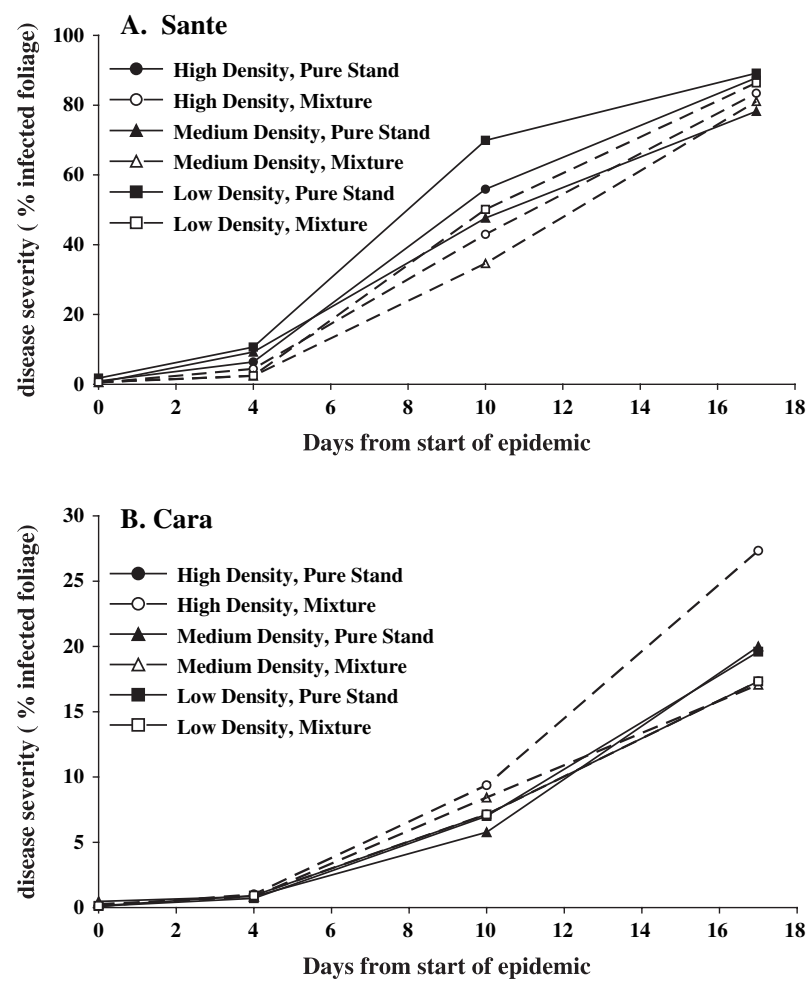

Figure 2 Potato late blight progress curves in 2002 on (A) Cara and (B) Sante in pure stands and mixtures with Sante or Cara at three planting densities.

that late blight severity increased with plot size towards an asymptote. Lipps \& Madden (1992) found that small plots of winter wheat had lower levels of powdery mildew Blumeria graminis than large plots, and that the dispersal gradient of B. graminis is similar to that of $P$. infestans. Similar effects of plot size have also been described for Mycosphaerella graminicola on wheat and Pyrenophora teres on barley (Burleigh \& Loubane, 1984).

These effects occur because the proportion of inoculum lost from plots decreases with increasing plot size and because the probability of an initial focus forming from

Table 5 Mean area under the disease progress curve (\%-day) of cvs. Cara and Sante in mixtures with other varieties

\begin{tabular}{llcr}
\hline & & \multicolumn{2}{l}{ Variety A } \\
\cline { 3 - 4 } Variety B & Proportion & Cara $^{\mathrm{a}}$ & Sante $^{\mathrm{b}}$ \\
\hline Cara & 0.5 & 325 & 1683 \\
Sante & 0.5 & 333 & 1129 \\
Appell & 0.5 & 59 & 531 \\
Tominia & 0.5 & 142 & 1046 \\
75\% Tominia & 0.75 & 66 & 862 \\
SED, 16 d.f. & & 76.9 & 282 \\
\hline
\end{tabular}

aDifferences between mixture partners, 4,16 d.f., $P<0.01$.

${ }^{b}$ Differences between mixture partners, 4,16 d.f., $P<0.05$. 
external inoculum is less in any given smaller plots. In the 2002 trial, the small plots occupied the same overall area as the medium and large plots, so the total probability of infection was the same regardless of plot size (assuming the inoculum arrived at random). However, in a group of small plots, resistant plots may have slowed the spread of spores into less infected susceptible plots. The effectiveness of this depends on the level of the resistance in that genotype; on resistant genotypes, more spores will be received than otherwise, and in fact, there was a small but significant increase in disease severity on Appell in the small plots, presumably because of this (Table 3).

Although AUDPC was lower in the smaller plots in 2002, the rate of disease progress was actually higher. Interplot interference and the delayed epidemic on the smaller plots explain this. As the epidemic was up to a week more advanced in the large plots, the spores distributed from these plots would have increased disease progress on the smaller plots during the middle of the general epidemic. This effect would increase the apparent rate of disease progress on the smaller plots, as observed.

This leads to the conclusion that if diversity is available for plant resistance against late blight, then disease severity will be reduced if any given mixture or variety is grown in more smaller plots rather than in fewer larger plots. This would especially be the case for simple mixtures of an immune and a susceptible variety or when the nonpotato area is occupied by immune material. Fleming et al. (1982) also suggested that the perimeter to area ratio of a field is roughly proportional to the rate of losses of pathogen spores from that field. Since the perimeter to area ratio increases as area decreases for fields of a given shape, small fields may sustain less disease than large fields.

In the UK setting, it is sensible to assume that racespecific variation in the pathogen is unimportant because matching virulences to all combinations of deployed Rgenes is common. Then, reducing the GUA will have little effect if external inoculum is common because the advantage to the susceptible variety will be offset by disadvantages to the more resistant variety (also see Connolly et al., 1995). It is not clear whether there is a proportional response to reducing GUA in mixtures incorporating rate-reducing resistance. However, the results discussed above indicate that the benefits of improving the autoinfection : alloinfection ratio by reducing the GUA are heavily dependent on the resistance level and resistance type of the more resistant genotypes. It is possible that the performance of some mixtures will be better at larger GUAs, as the negative impact of spores on the more resistant variety will be less. This implies that there is an optimal GUA, dependent on the level and type of resist- ance being diversified and the dispersal characteristics of the pathogen. If race-specific variation is important in the mixture effect, and the pathogen is a mixture of simple races, then the usual arguments imply that the most intimate mixture will give the greatest effect.

Table 5 illustrates the importance of resistance levels in the performance of variety diversification to prevent late blight. Appell and Tominia sustained negligible late blight in 2003. In the case of Appell, this is likely to be due to a useful major gene, and may therefore be unstable. In the case of Tominia, one of the Hungarian Sarpo family of potatoes, there is a high level of race nonspecific resistance (D. Shaw, personal communication). The importance of resistance levels is illustrated in the effect of mixing Cara with Sante. Fig. 2 and Table 5 show that Cara can restrict disease progress on Sante in variety mixtures, but the 2001 experiment shows that the effect is not reliable. This is probably because Cara itself is not immune and does not ordinarily have useful major genes in the UK. Also, Sante is a small, determinate variety, whereas Cara is a tall, spreading plant; this can create a damper microclimate in a mixed canopy than in a pure Sante crop, and encourage disease instead of restricting it. This probably happened in 2003, when the late blight epidemic was slowed by dry conditions during August. This is also likely to be the reason that Sante/Appell mixtures restricted late blight more than Sante/Tominia mixtures: Tominia foliage resembles Cara foliage, and Appell foliage resembles Sante foliage. In 2003, mixtures of Cara and Sante with Appell had substantially less disease than mixtures with Tominia, although both varieties were nearly immune and had similar epidemiological effects in spacing the Cara and Sante plants and acting as 'immune' barriers to spore dispersal.

As discussed above, Table 5 shows that the relative resistance ratios of potato varieties are crucial to the performance of variety mixtures. Race nonspecific late blight resistance is genetically linked to late maturity (Thurston, 1971). This is an agronomic problem as the varieties to be mixed should be agronomically compatible, especially in maturity class. However, the largest epidemiological effects of diversification are in simple mixtures of an immune and susceptible, or where one or other of the varieties has functioning major gene resistance. Race-specific resistance is not linked to maturity class. Therefore, potato variety mixtures to prevent late blight epidemics should diversify race nonspecific resistance as far as possible and also diversify for major gene resistances for which matching virulence is rare. Garrett \& Mundt (2000) also arrive at this conclusion, stating that, even if a sizeable proportion of the pathogen population has genes for overcoming the particular forms of qualitative resistance, deployment of genes for qualitative 
resistance in mixtures may still partition the pathogen population so that overall disease levels are reduced.

As Garrett \& Mundt (2000) point out, host-diversity effect might be expected to be greater at higher planting densities because single plants, and thus genotypes, occupy smaller areas as density increases, which will reduce autoinfection. If an interaction between planting density and mixture effects could be identified, this would further highlight the function of the dilution of susceptibles and barrier effects in the prevention of disease. In Fig. 2, there was neither an evidence for an effect of planting density on late blight severity nor any interaction between planting density and mixing. This confirms the results of Garrett et al. (2001), who report that there was no evidence for an influence of planting density on host-diversity effects for potato late blight. It seems that the mechanisms operating in the prevention of late blight by variety mixtures cannot be augmented by adjusting planting density within agriculturally relevant limits.

Garrett \& Mundt (2000) reported consistent reductions in late blight severity under both focal and general patterns of primary inoculum, in mixtures of a highly resistant variety with a susceptible variety. Field trials of potato mixtures near Quito, Ecuador, did not reflect these results (Garrett et al., 2001), possibly because external inoculum swamped mixture effects within plots. However, Garrett et al. (2001) used small plots and none of the varieties used had a level of resistance equivalent to the more resistant variety reported in Garrett \& Mundt (2000) or that of Appell and Tominia in the present study. All these results suggest that the epidemiological effects of potato variety mixtures are based mainly on replacing susceptible plants with resistant ones, so such mixtures will work best in large plots and with the best resistance available.

The use of variety mixtures to prevent plant diseases is an ecological approach to the problem of crop diseases. Potato mixtures exhibit important plant-plant interactions as well as plant-pathogen interactions, which may be thought of as resulting in a typical 'ecological combining ability' for each variety (Phillips, 2004). Furthermore, Phillips (2004) showed that cultivars with positive general ecological combining ability are characterised by very strong intracultivar competition in pure stands. Yield improvements of between $5 \%$ and $10 \%$ have been routinely recorded in potato variety mixtures (Phillips, 2004; M. Finckh, personal communication). Therefore, potato variety mixtures should be designed to improve yield of more resistant varieties by reducing the negative effects of intracultivar competition and to improve the yield of more susceptible varieties by reducing disease through mixture with a resistant variety. Diversification in this way could reduce the inputs needed to grow potatoes below those typical of large-scale monocultures (Phillips et al. 2002).

\section{References}

Akem C., Ceccarelli S., Erskine W., Lenne J. (2000) Using genetic diversity for disease resistance in agricultural production. Outlook on Agriculture, 29, 25-30.

Andrivon D., Lucas J.M., Ellisseche D. (2003) Development of natural late blight epidemics in pure and mixed plots of potato cultivars with different levels of partial resistance. Plant Pathology, 52, 586-596.

Bourke P.M.A. (1964) Emergence of potato blight, 1843-46. Nature, 203, 805-808.

Burleigh J.R., Loubane M. (1984) Plot size effects on disease progress and yield of wheat infected by Mycosphaerella graminicola and barley infected by Pyrenophora teres. Phytopathology, 74, 545-549.

Campbell C.L., Madden L.V. (1990) Introduction to Plant Disease Epidemiology. New York: Wiley-Interscience.

Connolly T., McNicol J.W., Wastie R.L., Stewart H.E. (1995) Evaluating between-plant interference in field trials for assessing potato genotypes for resistance to late blight. Annals of Applied Biology, 127, 273-282.

Finckh M.R., Wolfe M.S. (1998) The Epidemiology of Plant Diseases: Diversification Strategies, Ch. 11, pp. 231-259. Ed. G.D. Jones. Dordrecht, The Netherlands: Kluwer.

Fleming R.A., Marsh L.M., Tuckwell H.C. (1982) Effect of field geometry on the spread of crop disease. Protection Ecology, 4, 81-108.

Garrett K.A., Mundt C.C. (1999) Epidemiology in mixed host populations. Phytopathology, 89, 984-990.

Garrett K.A., Mundt C.C. (2000) Host diversity can reduce potato late blight severity for focal and general patterns of primary inoculum. Phytopathology, 90, 1307-1312.

Garrett K.A., Nelson R.J., Mundt C.C., Chacon G., Jaramillo R.E., Forbes G.A. (2001) The effects of host diversity and other management components on epidemics of potato late blight in the humid highland tropics. Phytopathology, 91, 993-1000.

James C. (1971) A Manual of Assessment Keys for Plant Diseases. Canada Department of Agriculture. Publication No. 1458. (Reprinted: St Paul, Minnesota: APS Press).

Jarosz A.M., Burdon J.J. (1991) Host-pathogen interactions in natural populations of Linum marginale and Melampsora lini. II. Local and regional variation in patterns of resistance and racial structure. Evolution, 45, 1618-1627.

Lipps P.E., Madden L.V. (1992) Effects of plot size and border width on assessment of powdery mildew of winter wheat. Plant Disease, 76, 299-303.

Mundt C.C. (2002) Use of multiline cultivars and cultivar mixtures for disease management. Annual Review of Phytopathology, 40, 381-410. 
Mundt C.C., Leonard K.J. (1985) Effect of host genotype unit area on epidemic development of crown rust following focal and general inoculations of mixtures of immune and susceptible oat plants. Phytopathology, 75, 1141-1145.

Mundt C.C., Cowger C., Garrett K.A. (2002) Relevance of integrated disease management to resistance durability. Euphytica, 124, 245-252.

Paysour R.E., Fry W.E. (1983) Interplot interference: a model for planning field experiments with aerially disseminated pathogens. Phytopathology, 73, 1014-1020.

Phillips S.L. (2002) Variety mixtures and the blighted organic potato. In Proceedings of the BCPC Conference - Pests $\theta$ Diseases, Eds. British Crop Protection Council Brighton, pp. 737-740. Farnham, Surrey: British Crop Protection Council.

Phillips S.L. (2004) The ecology and epidemiology of potato variety mixtures in organic potato production. $\mathrm{PhD}$ Thesis, the University of Reading, UK.
Phillips S.L., Leifert C., Santos J., Juntharathep P., Bodker L., Tamm L., Smit A.B. (2002) Development of a systems approach for the management of late blight (Phytophthora infestans) in organic potato production: an update on the EU Blight-MOP project. In Proceedings of the BCPC conference - Pests $\theta$ Diseases, Eds. British Crop Protection Council, Brighton, pp. 539-546. Farnham, Surrey: British Crop Protection Council.

Thurston H.D. (1971) Relationship of general resistance: late blight of potato. Phytopathology, 61, 620-626.

Wolfe M.S. (1985) The current status and prospects of multiline cultivars and variety mixtures for disease resistance. Annual Review of Phytopathology, 23, 251-273.

Zhu Y., Chen H., Fan J., Wang Y., Li Y., Chen J., Fan J., Yang S., Hu L., Leung H., Mew T.W., Teng P.S., Wang Z., Mundt C.C. (2000) Genetic diversity and disease control in rice. Nature, 406, 718-722. 